\title{
Novel Molecular Aspects of Ghrelin and Leptin in the Control of Adipobiology and the Cardiovascular System
}

\author{
Amaia Rodríguez $z^{a, b}$ \\ a Metabolic Research Laboratory, Clínica Universidad de Navarra, Pamplona, b CIBER \\ Fisiopatología de la Obesidad y Nutrición, Instituto de Salud Carlos III, Spain
}

\section{Key Words}

Adipocyte - Adipokines - Appetite - Blood pressure - Cardiometabolic risk - Cardiovascular disorders · Energy balance · Ghrelin · GOAT · Hypertension

\begin{abstract}
Ghrelin and leptin show opposite effects on energy balance. Ghrelin constitutes a gut hormone that is secreted to the bloodstream in two major forms, acylated and desacyl ghrelin. The isoforms of ghrelin not only promote adiposity by the activation of hypothalamic orexigenic neurons but also directly stimulate the expression of several fat storage-related proteins in adipocytes, including ACC, FAS, LPL and perilipin, thereby stimulating intracytoplasmic lipid accumulation. Moreover, both acylated and desacyl ghrelin reduce TNF- $\alpha$-induced apoptosis and autophagy in adipocytes, suggesting an anti-inflammatory role of ghrelin in human adipose tissue. On the other hand, leptin is an adipokine with lipolytic effects. In this sense, leptin modulates via PI3K/Akt/mTOR the expression of aquaglyceroporins such as AQP3 and AQP7 that facilitate glycerol efflux from adipocytes in response to the lipolytic stimuli via its translocation from the cytosolic fraction (AQP3) or lipid droplets (AQP7) to the plasma membrane. Ghrelin and leptin also participate in the homeostasis of the cardiovascular system. Ghrelin operates as a cardioprotective factor with increased circulating acylated ghrelin concentrations in patients with left ventricular hypertrophy (LVH) causally related to LV remodeling during the progression to LVH. Additionally, leptin induces vasodilation by inducible NO synthase expression (iNOS) in the vascular wall. In this sense, leptin inhibits the angiotensin II-induced $\mathrm{Ca}^{2+}$ increase, contraction and proliferation of VSMC through NO-dependent mechanisms. Together, dysregulation of circulating ghrelin isoforms and leptin resistance associated to obesity, type 2 diabetes, or the metabolic syndrome contribute to cardiometabolic derangements observed in these pathologies.

(c) 2014 S. Karger GmbH, Freiburg
\end{abstract}

Amaia Rodríguez, PhD

Metabolic Research Laboratory

Clínica Universidad de Navarra

Irunlarrea 1, 31008 Pamplona (Spain)

arodmur@unav.es 
Rodríguez et al.: Novel Molecular Aspects of Ghrelin and Leptin in the Control of Adipobiology and the Cardiovascular System

\section{Introduction}

Obesity is a serious health problem, becoming one of the leading causes of death and morbidity worldwide [1]. In 2008, 1.5 billion adults were overweight with an estimated 500 million adults worldwide being obese; thus, approximately $65 \%$ of the world's population inhabit countries where overweight and obesity kill more people than underweight $[1,2]$. Obesity is closely associated to the development of dyslipidemia, insulin resistance, and hypertension that are all well-known risk factors for cardiovascular disease [3]. In this regard, the regional fat distribution is important for the development of the metabolic syndrome and its accompanying cardiovascular complications. Upper body obesity (i.e. visceral or android obesity), as determined by an increased waist circumference and waist-to-hip ratio or elevated visceral or central fat area by image analysis at the lumbosacral level, is associated with increased incidence of metabolic disturbances, elevated risk of cardiovascular disease, and premature death $[4,5]$. The adipose tissue constitutes an important source of circulating mediators of inflammation that participate in the mechanisms of cardiovascular injury and atheromateous change $[3,6]$. In this sense, adipocytes and adipose tissue-embedded immune cells secrete multiple pro-inflammatory cytokines (TNF- $\alpha$, IL-6, osteopontin), acute-phase reactants (CRP, SAA), complement factors (adipsin and ASP), prothrombotic molecules (PAI-1, tissue factor), and growth factors (cardiotrophin-1, EGF, FGF). The present review focuses on the participation of leptin and ghrelin, two key hormones in the regulation of energy balance, in the control of adiposity and cardiovascular homeostasis.

\section{The Components of the Ghrelin System}

Ghrelin is a 28-amino acid peptide hormone synthesized by X/A-like cells of the oxyntic glands in the mucosa of the gastric fundus [7]. Although stomach and intestine constitute the two major ghrelin-secreting tissues [8], other tissues express ghrelin, to a lesser extent, including pancreas, kidney, gonads, heart or adipose tissue [9]. The human GHRL gene is located on chromosome 3p26-p25 and encodes a polypeptide of 117 amino acids, named preproghrelin, which is proteolytically processed to yield two peptides, ghrelin and obestatin [7, 10]. Two major forms of ghrelin are present in plasma and stomach: acylated ghrelin (form with the $n$-octanoyl modification at Ser3) and desacyl-ghrelin (form without the acylation) [11]. Under physiological conditions, the ratio of acylated ghrelin / desacyl ghrelin ranges in general from $1: 3$ to $1: 4$, but this ratio varies under pathological conditions such as chronic atrophic gastritis, chronic renal disease, anorexia nervosa, obesity, type 2 diabetes, or metabolic syndrome [1216]. Other shorter forms of ghrelin have been described, such as des-Gln14-ghrelin, but their role remains unknown [17]. The acylation of ghrelin is catalyzed by the porcupine-like enzyme ghrelin $O$-acyltransferase (GOAT) in the endoplasmic reticulum (ER) $[18,19]$.

The growth hormone (GH) secretagogue receptor (GHS-R) is a G protein-coupled receptor that binds ghrelin and acts on the pituitary gland and hypothalamus to stimulate $\mathrm{GH}$ release [20]. The human GHSR gene maps on chromosome 3q26.31, and two transcripts are produced from the alternative splicing of this gene: GHS-R $1 \mathrm{a}$ and $1 \mathrm{~b}$. The transcript GHS-R $1 \mathrm{a}$ excises an intron, encodes a protein with 366 amino acids with seven transmembrane domains, and is considered the functional ghrelin receptor $[20,21]$. The second transcript, GHS-R $1 \mathrm{~b}$, retains the intron, encodes a C-terminally truncated isoform of the ghrelin receptor, consisting of 289 amino acids and five transmembrane domains, and does not stimulate GH release. Nevertheless, GHS-R 1b can attenuate the activity of GHS-R 1a by the formation of heterodimers [22]. It has been recently described that the orphan receptor $G$ protein-coupled receptor 83 (GPR83) also forms heterodimers with GHS-R 1a diminishing its activation by acylated ghrelin [23]. 
Rodríguez et al.: Novel Molecular Aspects of Ghrelin and Leptin in the Control of Adipobiology and the Cardiovascular System

\section{Leptin and Leptin Receptors}

Leptin, the product of the obese $(O B)$ gene, is a $16-\mathrm{kDa}$ protein mainly produced and secreted by adipocytes [24]. Etymologically, the name is derived from the Greek word leptos, meaning thin, in reference to the anti-obesity effect of the hormone, which initially was believed to be its primary physiological function [25]. The human leptin gene (LEP) resides in chromosome 7q31.3 and encodes a protein with a tertiary structure of leptin resembling that of the long-chain helical cytokine family members [26]. Crystallization and nuclear magnetic resonance studies of leptin showed a cytokine-like folding with four antiparallel $\alpha$-helices, connected by two long crossover links and one short loop arranged in a lefthanded helical bundle [27], which forms a two-layer packing. The two cysteine residues of the C-terminus (Cys 96 and 146) form a disulphide bond, which is the key to the biological effects of the protein [28]. The secretion of leptin is proportional to the total amount of body fat, and its circulating concentrations are markedly increased in obesity [29]. In this sense, serum leptin levels range from 1 to $15 \mathrm{ng} / \mathrm{ml}$ in non-obese individuals, but reach levels higher than $30 \mathrm{ng} / \mathrm{ml}$ in subjects with a BMI $\geq 30 \mathrm{~kg} / \mathrm{m}^{2}$ [30]. Moreover, there is a sexual dimorphism in circulating leptin levels with women showing higher leptin concentrations than men [31].

Leptin receptors (OB-R) show structural resemblance to the class I cytokine receptor family, and their ubiquitous distribution underlies the multifunctionality of leptin [32,33]. At least, six alternative spliced isoforms of the receptor have been identified in rodents, designated OB-Ra, OB-Rb, OB-Rc, OB-Rd, OB-Re and OB-Rf [32], which share a common extracellular domain of over 800 amino acids, a 34-amino acid transmembrane domain and a variable intracellular domain, characteristic for each of the isoforms, with the exception of OB-Re, which lacks the intracellular domain and is a soluble receptor.

\section{The Role of Leptin and Ghrelin in the Regulation of Body Weight and Adiposity}

The hypothalamus integrates changes in adiposity hormones, gastric hormones, and nutrients to control the food intake [34]. There are two subtypes of hypothalamic neurons regulating food intake: i) neurons containing the orexigenic peptides neuropeptide Y (NPY) and agouti-related peptide (AgRP) and, to a lesser extent, galanin and ghrelin; and ii) neurons containing anorexigenic peptides such as proopiomelanocortin (POMC) and cocaine- and amphetamine-regulated transcript (CART) and, to a lesser extent, neurotensin. These hypothalamic circuits are regulated by energy status and several circulating hormones, including ghrelin and leptin, that show opposite effects on appetite and adiposity.

\section{Anorexigenic and Lipolytic Effect of Leptin}

Leptin reduces food intake and increases energy expenditure to maintain the energy balance [25]. Central administration of leptin results in an activation of several hypothalamic nuclei including the arcuate nucleus (ARC), ventromedial hypothalamus (VMN) and dorsomedial hypothalamus (DMN), all areas involved in the regulation of feeding behavior and energy balance [35]. On binding its hypothalamic receptors, leptin activates anorexigenic neurons containing POMC and CART, decreasing food intake and body weight [35]. Furthermore, leptin increases energy expenditure through the stimulation of sympathetic nerve activity and the turnover of norepinephrine in brown adipose tissue (BAT) [36]. In this sense, leptin plays a crucial role in brown adipogenesis, since leptin-deficient $o b / o b$ mice show a 'white-like' appearance of BAT (large unilocular lipid droplets instead of the characteristic small multilocular lipid droplets in brown adipocytes) [37, 38]. Noteworthy, leptin 
Rodríguez et al.: Novel Molecular Aspects of Ghrelin and Leptin in the Control of Adipobiology and the Cardiovascular System

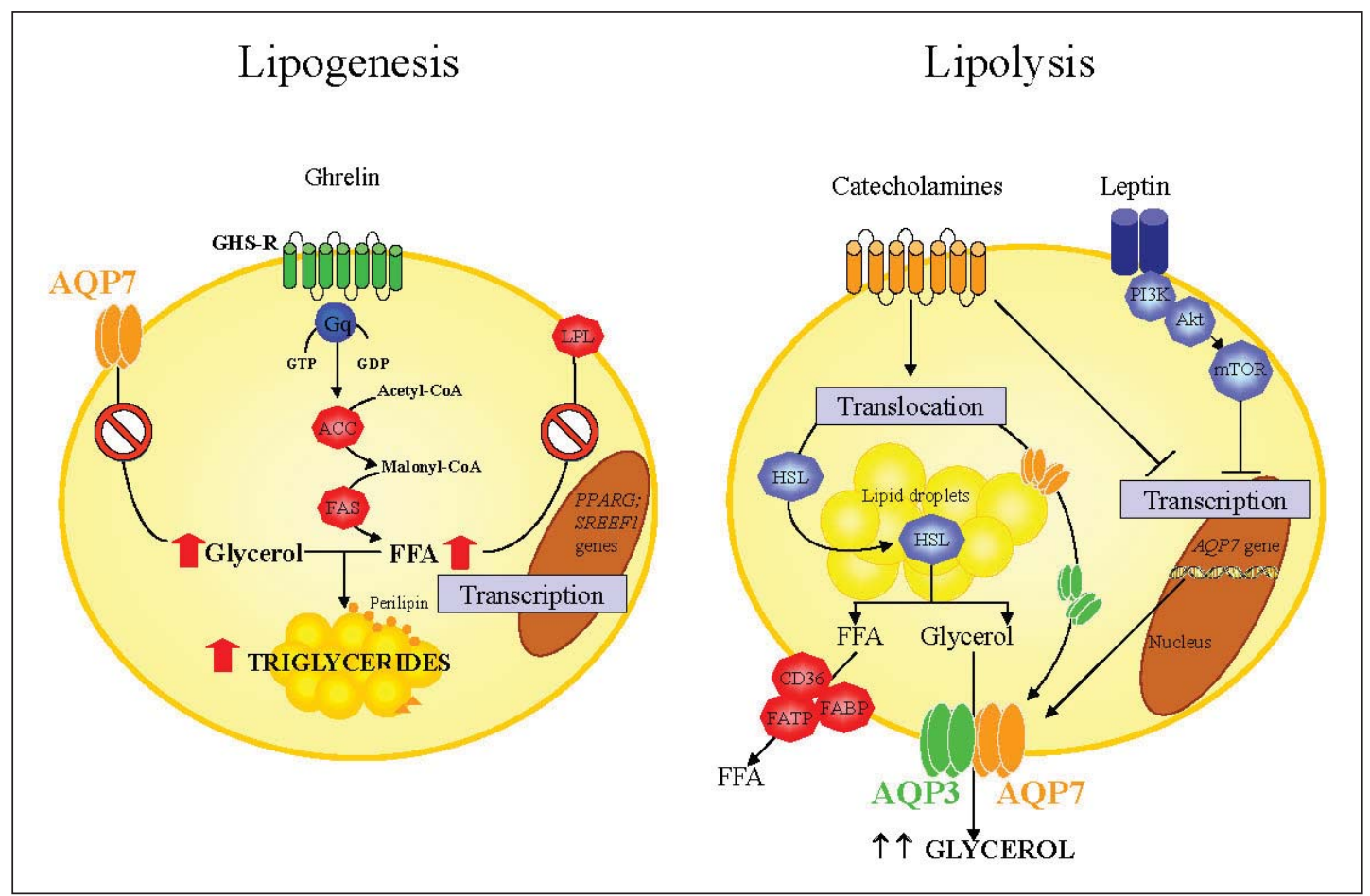

Fig. 1. Proposed role of ghrelin and leptin in lipogenesis and lipolysis, respectively. ACC = Acetyl-CoA carboxylase; $\mathrm{AQP}=$ aquaporin; $\mathrm{CD} 36$ = fatty acid translocase; FFA = free fatty acids; FABP = fatty acid binding protein; FAS = fatty acid synthase; FATP = fatty acid transporter protein; GHS-R = growth hormone secretagogue receptor; $\mathrm{HSL}=$ hormone sensitive lipase; $\mathrm{LPL}=$ lipoprotein lipase; $\mathrm{mTOR}=$ mammalian target of rapamycin; PI3K = phosphatidylinositol 3-kinase; PPARG = peroxisome proliferator-activated receptor $\gamma$ gene; SREBF1 = sterol regulatory element-binding factor 1 gene.

also exerts a direct lipolytic effect in white adipose tissue counteracting the tonic inhibition of lipolysis of adenosine deaminase [39].

In circumstances of negative energy balance, such as fasting or exercise, triacylglycerols are hydrolysed to glycerol and free fatty acids (fig. 1) [40, 41]. Lipoprotein (LPL) and fatty acid transporters (FABP, FATP and CD36) facilitate the transport of free fatty acids across the membrane. AQP7 has been considered the unique glycerol channel in the adipose tissue, but AQP3 and AQP9 represent novel additional pathways for the transport of glycerol in human adipocytes [42]. AQP3 and AQP7 show a cytosolic distribution upon the lipid droplets, and they are translocated to the plasma membrane in response to the lipolytic stimulation of isoproterenol, whereas AQP9 is constitutively expressed in the plasma membrane of adipocytes. Lypolityc stimuli, such as catecholamines by the stimulation of $\beta 1$-, $\beta 2$ - and $\beta 3$-adrenergic receptors or leptin on binding OB-R and activating PI3K/Akt/mTOR pathway, lead to the translocation of hormone-sensitive lipase (HSL) to the lipid droplets and its activation as well as to a parallel translocation of AQP3 and AQP7 to the plasma membrane to facilitate the glycerol release [42-44]. Interestingly, leptin and catecholamines down-regulate AQP7 expression, suggesting a negative feedback regulation in lipolytic states to restrict glycerol release from adipocytes [42]. 
Rodríguez et al.: Novel Molecular Aspects of Ghrelin and Leptin in the Control of Adipobiology and the Cardiovascular System

\section{Orexigenic and Adipogenic Effect of Ghrelin}

Ghrelin plays a major role in the short-term regulation of appetite and long-term regulation of body weight [9]. Circulating concentrations of ghrelin are characterized by a preprandial rise and a postprandial fall, supporting its role in meal initiation in humans [45]. Ghrelin promotes adiposity by increasing food intake through the stimulation of hypothalamic orexigenic neurons expressing NPY, AgRP, and orexin [46, 47]. The orexigenic actions of ghrelin require the activation of hypothalamic sirtuin-1 (SIRT1) / p53, AMP-activated protein kinase (AMPK), and mammalian target of rapamycin (mTOR) pathways, which ultimately increase NPY and AgRP expression in the arcuate nucleus [48-50]. Despite its orexigenic effect, obesity, insulin resistance, type 2 diabetes, and the metabolic syndrome are related to a paradoxical decrease in circulating ghrelin levels [7, 51, 52]. However, these pathologies are associated with a dramatic reduction of plasma desacyl ghrelin concentrations, the most abundant form of the hormone, while plasma levels of acylated ghrelin remain unchanged or increased [19, 53-55].

The adipose tissue also constitutes an important target for the adipogenic actions of ghrelin. All the components of the ghrelin system (ghrelin, GOAT and the receptors of ghrelin gene-related peptides GHS-R 1a and GPR39) are expressed in human adipose tissue [19, 53, 56], suggesting an autocrine/paracrine effect of ghrelin in this tissue. During adipogenesis, ghrelin gene (GHRL) expression is increased [57], and ghrelin stimulates the expression of the adipogenic transcription factors peroxisome proliferator-activated receptor $\gamma$ (PPAR $\gamma$ ) and sterol regulatory element-binding transcription factor 1 (SREBF1), and hence, promotes adipocyte differentiation (fig. 1) [53]. In addition, acylated and desacyl ghrelin stimulate the expression of several fat-storage related proteins such as acetyl-CoA carboxylase, fatty acid synthase, LPL or perilipin through central mechanisms [48] and directly acting on human adipocytes [53], thereby stimulating intracellular lipid accumulation. Moreover, ghrelin also has an antilipolytic action [58]. In this sense, acylated and desacyl ghrelin attenuate isoproterenol-induced lipolysis through phosphatidyl-inositol-3 kinase(PI3K)-dependent mechanisms in murine 3T3-L1 cells as well as in isolated rat visceral adipocytes [59]. In this line, the expression of AQP7 in human visceral adipocytes is repressed by acylated and desacyl ghrelin, supporting the view that ghrelin decreases lipolytic capacity and promotes fat cell enlargement [53].

In addition to promote adipogenesis and lipogenesis, ghrelin plays an anti-inflammatory role in the adipose tissue. Acylated and desacyl ghrelin inhibit the activation of caspases and apoptosis induced by TNF- $\alpha$, and also reduce basal and TNF- $\alpha$-induced expression of key autophagy-related genes [19]. In this sense, the imbalance of ghrelin isoforms and TNF- $\alpha$ in states of hyperglycemia may contribute to the altered apoptosis and autophagy observed in patients with type 2 diabetes.

\section{Implication of Leptin and Ghrelin in the Maintenance of Cardiovascular Homeostasis}

Obesity has been classified as a major modifiable risk factor for cardiovascular diseases [60]. Excess adiposity is associated with an increase in total blood volume, which, in turn, contributes to an increase in left ventricular (LV) preload and an increase in resting cardiac output (fig. 2) [61, 62]. The increased demand for cardiac output is achieved by an increase in stroke volume, while the heart rate remains comparatively unchanged. The obesity-related increase in stroke volume results from an increase in LV diastolic filling. The increase in circulatory preload and afterload lead to LV dilatation. An elevated cardiac output is common with moderate obesity, but not all obese patients are hypertensive. However, in those subjects 


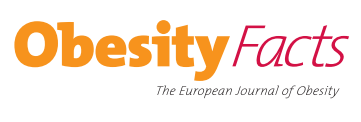

\begin{tabular}{l|l}
\hline Obes Facts 2014;7:82-95 & $\begin{array}{l}\text { ○ 2014 S. Karger GmbH, Freiburg } \\
\text { www.karger.com/ofa }\end{array}$ \\
\hline DOI: 10.1159/000360837 &
\end{tabular}

Rodríguez et al.: Novel Molecular Aspects of Ghrelin and Leptin in the Control of Adipobiology and the Cardiovascular System

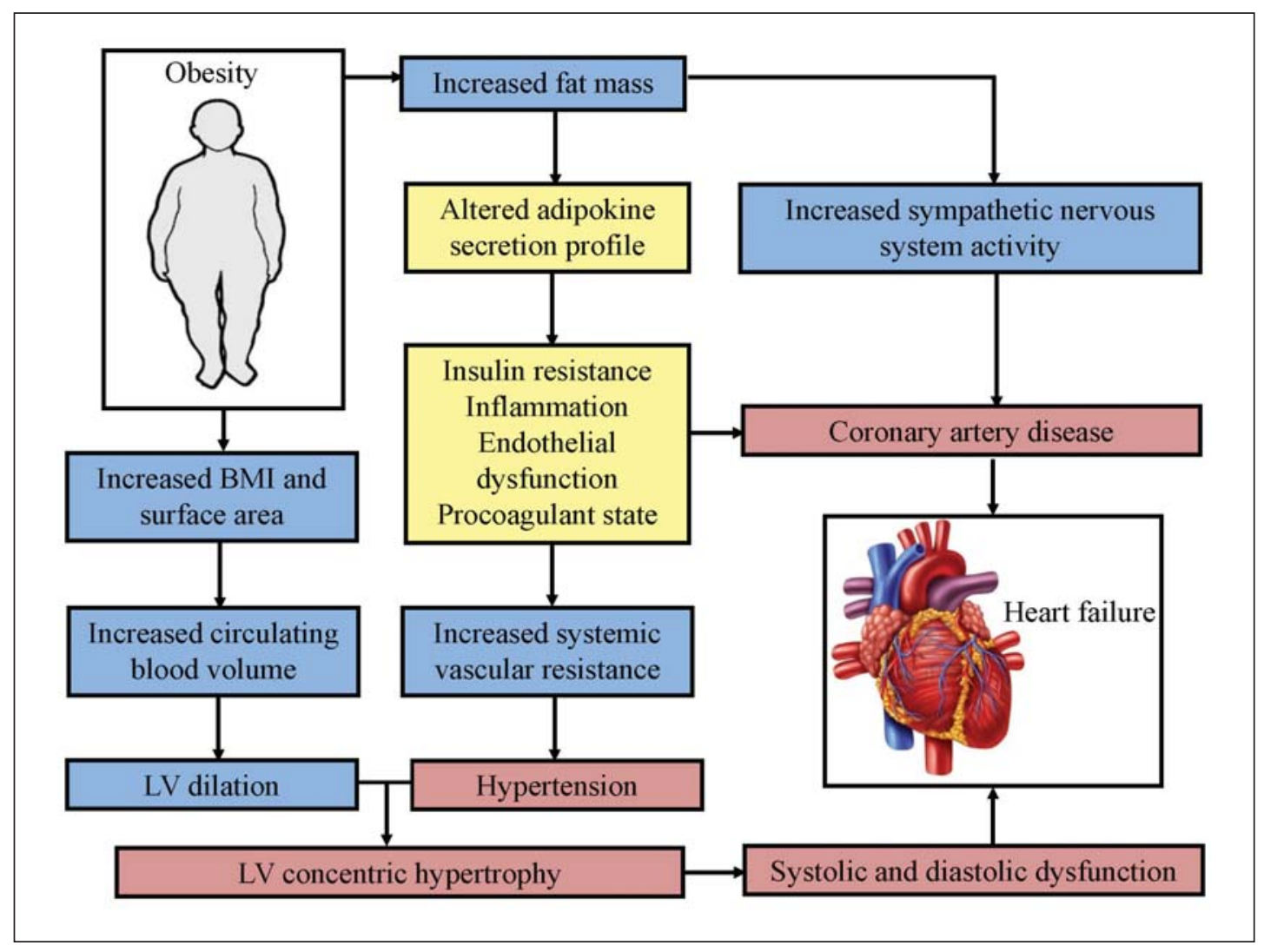

Fig. 2. Schematic diagram of obesity-associated cardiovascular alterations leading to heart failure. $L V=L e f t$ ventricle.

where systemic vascular resistance is increased, the combination of obesity and hypertension results in an increase of $\mathrm{LV}$ wall dimensions disproportionate to the chamber radius, and this leads, in turn, to LV concentric hypertrophy. In addition to increased blood pressure values, obese subjects exhibit elevated cardiovascular risk factors which alter vascular function, adding further to the pressure load of the heart [61]. Despite an elevation of cardiac output, obese individuals have been shown to present a depressed myocardial contractility proportional to excess body weight. LV hypertrophy together with reduced ventricular compliance results in diastolic dysfunction; a combination of systolic and diastolic dysfunction progresses to a clinically significant risk of heart failure. In this section, we will focus on the role of leptin and ghrelin in the homeostasis of cardiovascular system.

\section{Vascular Effects of Leptin}

Leptin plays two opposite roles in the regulation of blood pressure by exerting a hypertensive effect due to the sympathoactivation [63] and a vasorelaxant action due to the release of NO in the aorta and coronary arteries and endothelial-derived hyperpolarizing factor in mesenteric arteries (EDHF) [64-67]. On the one hand, intracerebroventricular leptin administration increases blood pressure by increasing sympathetic activity [68]. However, leptin also induces vasodilation by increasing NO bioavailability in peripheral blood vessels through the activation of endothelial NO synthase (eNOS) in endothelial cells [69] and inducible NO synthase (iNOS) in vascular smooth muscle cells (VSMC) [70]. Moreover, leptin inhibits angiotensin II-induced contraction of vascular smooth muscle cells $[70,71]$. Leptin attenuates 
Rodríguez et al:: Novel Molecular Aspects of Ghrelin and Leptin in the Control of

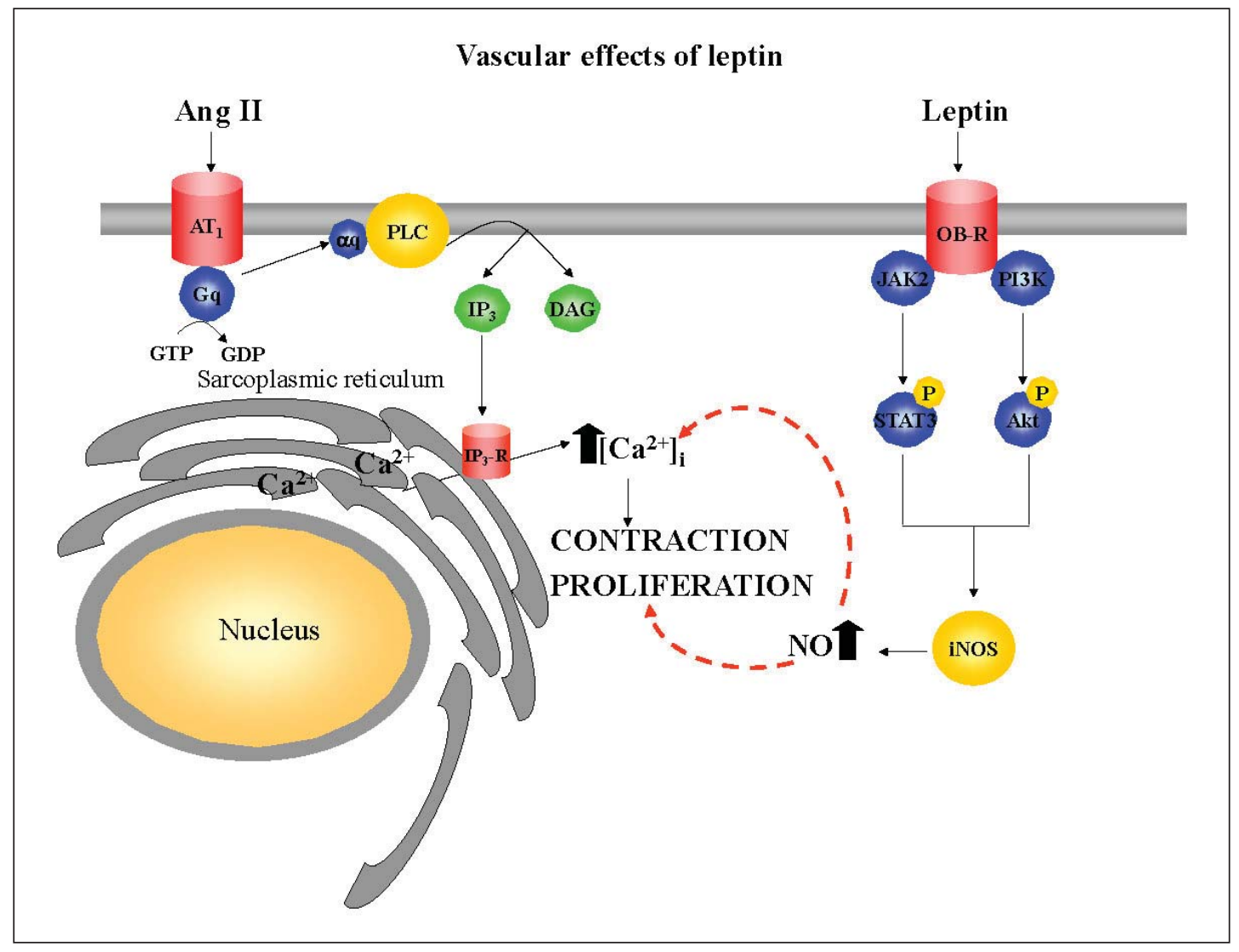

Fig. 3. Proposed mechanism for the actions of leptin on vascular smooth muscle cell contraction and proliferation. Ang II = Angiotensin II; AT1 = angiotensin II receptor type 1; DAG = diacylglycerol; JAK = janus kinase; iNOS = inducible nitric oxide synthase; IP3 = inositol triphosphate; NO = nitric oxide; PI3K = phosphatidylinositol 3-kinase; PLC = phospholypase C; STAT = signal transducer and activator of transcription.

angiotensin II-induced release of $\mathrm{Ca}^{2+}$ sequestered in the intracellular stores of VSMC that represents the major mechanism used by angiotensin II to induce vasoconstriction (fig. 3). This inhibitory effect of leptin requires the up-regulation of iNOS via the activation of the JAK/ STAT and PI3K/Akt pathways [70]. A further mechanism whereby leptin decreases blood pressure is via the activation of natriuresis and diuresis through NO-dependent mechanisms [72].

Increased circulating concentrations of leptin are found in hypertensive animal models $[73,74]$ and humans $[75,76]$, suggesting a possible link between hyperleptinemia and hypertension. Interestingly, leptin enhances the expression of the NADPH oxidase isoform 2 (NOX2), and hence, the intracellular accumulation of reactive oxygen species (ROS) in the vascular wall $[77,78]$. Spontaneously hypertensive rats, an animal model with features of the metabolic syndrome, show increased NOX2 expression and impaired ability of leptin to inhibit the angiotensin II-induced increase of cytosolic $\mathrm{Ca}^{2+}$ and vasoconstriction in VSMC $[74,77,79]$. The hyperleptinemia, increased oxidative stress, and the loss of this anti-contractile effect of leptin suggest that this animal model of hypertension present vascular leptin resistance. In this sense, endothelial dysfunction is characterized by a reduced synthesis and release of endothelium-derived relaxing factors, such as NO and/or an enhanced production of ROS, which scavenge NO within vessels to reduce its biological half-life. Taken together, it could be 
Rodríguez et al.: Novel Molecular Aspects of Ghrelin and Leptin in the Control of Adipobiology and the Cardiovascular System

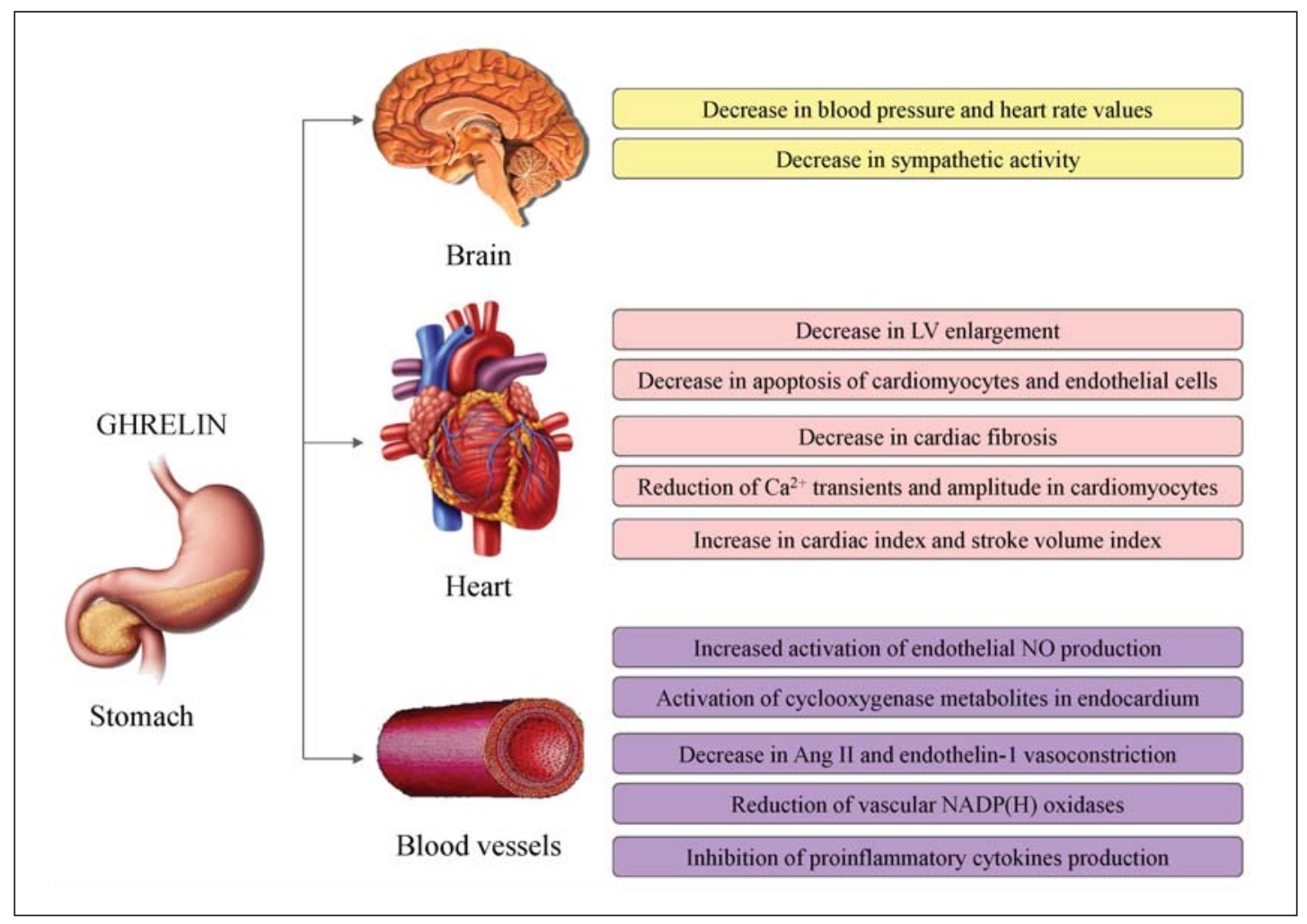

Fig. 4. Central and peripheral actions of ghrelin on the control of cardiovascular homeostasis. Ang II = Angiotensin II; LV = left ventricle; NADP(H) = nicotinamide adenine dinucleotide phosphate-oxidase.

speculated that, in the setting of hypertension, the vasodilatory effects of leptin are overridden by the effects of angiotensin II, the increased systemic oxidative stress as well as the excessive sympathoactivation, despite the hyperleptinemia.

Hypertension is associated with structural changes in blood vessels known as vascular remodeling that include an altered VSMC proliferation, hypertrophy, migration, and apoptosis together with an increased extracellular matrix abundance. Angiotensin II constitutes one of the main factors involved in vascular remodeling during the onset of hypertension. Our group has shown that leptin inhibits the proliferative response induced by angiotensin II, via NO-dependent mechanisms (fig. 3) [77]. However, VSMC from hypertensive rats are less responsive to the anti-proliferative effect of leptin, probably due to a reduction in NO bioavailability and increased oxidative stress. Nonetheless, the role of leptin on VSMC proliferation remains unclear, with reports showing either stimulatory [80, 81] or inhibitory $[77,82]$ effects on this biological process. Thus, the effect of leptin on VSMC proliferation seems to be complex, and further studies are needed to disentangle the potential involvement of leptin in vascular remodeling [83].

\section{Ghrelin as a Cardioprotective Hormone}

Growing evidence support the role of ghrelin in the control of cardiovascular homeostasis through central and peripheral mechanisms (fig. 4). Intracerebroventricular administration of ghrelin into the nucleus of the solitary tract, a region involved in the regulation of cardiovascular system, induces a decrease in blood pressure and heart rate and also suppresses sympathetic renal activity in experimental animals $[84,85]$. In addition, the myocardium 
Rodríguez et al.: Novel Molecular Aspects of Ghrelin and Leptin in the Control of Adipobiology and the Cardiovascular System

constitutes a source of ghrelin [86], and GHS-R 1a is expressed in cardiomyocytes and other myocardial cells, suggesting an autocrine/paracrine role of ghrelin in the heart [87]. Chronic administration of ghrelin improves cardiac performance in rats and humans with chronic heart failure (CHF), as indicated by increases in cardiac output, LV fractional shortening, and ejection fraction [88-90]. Moreover, a single dose of ghrelin after myocardial infarction prevents an increase in cardiac sympathetic nerve activity and reduces the high mortality rate associated with this pathology [91]. In this line, Ghrl knockout mice exhibit excessive sympathoactivation, impaired LV function, early cardiac remodeling, and higher mortality after myocardial infarction, a fact that further suggests the crucial role of ghrelin in the maintenance of heart function [88].

The mechanisms underlying the cardioprotective actions of ghrelin include: i) negative inotropism by activating the release of cyclooxygenase metabolites in endocardial endothelium and by reducing the amplitude and rising rate of cytosolic $\mathrm{Ca}^{2+}$ transients in cardiomyocytes [92,93]; ii) vasodilation by inducing endothelial NO release through PI3K-dependent mechanisms as well as by reducing endothelin-1, angiotensin II, and vascular NADP(H) oxidases activities [94-96]; iii) inhibition of apoptosis in cardiomyocytes and endothelial cells through activation of mitogen-activated protein kinase p42/44 (ERK1/2) and PI3K/Akt signaling pathways and by inhibiting the activation of the endoplasmic reticulum stress pathway [97, 98]; and iv) reduction of endothelial and cardiac inflammation through the inhibition of pro-inflammatory cytokine production, mononuclear cell binding and nuclear factor- $\kappa \mathrm{B}(\mathrm{NF}-\mathrm{\kappa B})$ in endothelial cells, as well as through the suppression of myocardial levels of TNF- $\alpha$ and IL-6 $[99,100]$.

Total ghrelin levels are decreased in several cardiovascular disorders, such as pregnancyinduced hypertension, essential hypertension, atherosclerosis, coronary heart disease, and CHF [101-104]. However, the specific role of ghrelin isoforms in these pathologies has not been completely disentangled. In this regard, the metabolic syndrome, an important risk factor for cardiovascular disease incidence and mortality, is related to higher plasma acylated ghrelin and lower concentrations of desacyl ghrelin [54]. Interestingly, acylated ghrelin is positively associated with LV mass and higher blood pressure in patients with the metabolic syndrome, suggesting a role of this isoform of the hormone in the progression of LV hypertrophy and other cardiovascular complications in these patients.

\section{Conclusions}

Weight gain is accompanied by progressive physiological changes in cardiovascular function that can lead to heart failure [61]. It is well established that a modest weight loss ranging from 5 to $10 \%$ of the initial body weight by means of diet, exercise, or bariatric surgery results in an improvement of obesity-associated cardiometabolic disturbances [3]. Epidemiological and interventional studies have shown the beneficial effects of weight loss on cardiovascular mortality and morbidity due to favorable implications on LV hypertrophy as well as beneficial effects on coronary risk [105].

Obesity is associated with hyperleptinemia, an imbalance of ghrelin isoforms as well as with an impairment of transduction signal in effector organs, suggesting the pivotal role of leptin and ghrelin in the control of adiposity and cardiovascular homeostasis. Sleeve gastrectomy, an effective bariatric procedure for the treatment of morbid obesity, is associated with a reduction of blood pressure, but not heart rate, in genetically obese Zucker $\mathrm{fa}$ / $f a$ rats beyond weight loss [106]. The same was true in an animal model of diet-induced obesity that showed a further reduction of heart rate values without loss of cardiac mass [107]. Interestingly, sleeve gastrectomy is associated with a dramatic reduction of circulating 
Rodríguez et al.: Novel Molecular Aspects of Ghrelin and Leptin in the Control of Adipobiology and the Cardiovascular System

leptin and ghrelin concentrations. It seems plausible that the decrease in leptin and ghrelin concentrations together with the improved intracellular signaling in the adipose tissue and cardiovascular system play a key role in the reduction of obesity-associated cardiometabolic alterations. In line with this observation, a recent study has shown that the offspring of rabbits exposed to high-fat diet during pregnancy exhibited an increase in sympathetic renal activity and blood pressure due to an altered central hypothalamic sensitivity to ghrelin and leptin [108]. Given the current prevalence of obesity, better understanding the underlying mechanisms that relate fat mass to cardiovascular health induced by leptin and ghrelin is of paramount importance, since obesity is a major modifiable contributor to cardiovascular disease.

\section{Acknowledgement}

This work was funded by the Instituto de Salud Carlos III (FIS PI10/01677 and PI13/01430) and the Plan de Investigación de la Universidad de Navarra (PIUNA) (2011-2014). CIBER de Fisiopatología de la Obesidad y Nutrición (CIBERobn) is an initiative of the Instituto de Salud Carlos III, Spain.

\section{Disclosure Statement}

The author declares no conflict of interests.

\section{References}

1 Frühbeck G, Toplak H, Woodward E, Yumuk V, Maislos M, Oppert JM: Obesity: The gateway to ill health - an EASO position statement on a rising public health, clinical and scientific challenge in Europe. Obes Facts 2013; 6:117-120.

-2 Finucane MM, Stevens GA, Cowan MJ, Danaei G, Lin JK, Paciorek CJ, et al: National, regional, and global trends in body-mass index since 1980: systematic analysis of health examination surveys and epidemiological studies with 960 country-years and 9.1 million participants. Lancet 2011;377:557-567.

-3 Rodríguez A, Catalán V, Gómez-Ambrosi J, Frühbeck G. Visceral and subcutaneous adiposity: are both potential therapeutic targets for tackling the metabolic syndrome? Curr Pharm Des 2007;13:2169-2175

- Kuk JL, Katzmarzyk PT, Nichaman MZ, Church TS, Blair SN, Ross R: Visceral fat is an independent predictor of all-cause mortality in men. Obesity (Silver Spring) 2006;14:336-341.

-5 Yusuf S, Hawken S, Ounpuu S, Bautista L, Franzosi MG, Commerford P, et al: Obesity and the risk of myocardial infarction in 27,000 participants from 52 countries: a case-control study. Lancet 2005;366:1640-1649.

6 Frühbeck G: The adipose tissue as a source of vasoactive factors. Curr Med Chem Cardiovasc Hematol Agents 2004;2:197-208.

7 Kojima M, Hosoda H, Date Y, Nakazato M, Matsuo H, Kangawa K: Ghrelin is a growth-hormone releasing acylated peptide from stomach. Nature 1999;402:656-660.

8 Frühbeck G, Diez Caballero A, Gil MJ: Fundus functionality and ghrelin concentrations after bariatric surgery. N Engl J Med 2004;350:308-309.

-9 Chen CY, Asakawa A, Fujimiya M, Lee SD, Inui A: Ghrelin gene products and the regulation of food intake and gut motility. Pharmacol Rev 2009;61:430-481.

$\checkmark 10$ Zhu X, Cao Y, Voogd K, Steiner DF: On the processing of proghrelin to ghrelin. J Biol Chem 2006;281:3886738870 .

11 Hosoda H, Kojima M, Matsuo H, Kangawa K: Ghrelin and des-acyl ghrelin: two major forms of rat ghrelin peptide in gastrointestinal tissue. Biochem Biophys Res Commun 2000;279:909-913.

12 Campana D, Nori F, Pagotto U, De Iasio R, Morselli-Labate AM, Pasquali R, et al: Plasma acylated ghrelin levels are higher in patients with chronic atrophic gastritis. Clin Endocrinol (Oxf) 2007;67:761-766.

13 Tong J, Dave N, Mugundu GM, Davis HW, Gaylinn BD, Thorner MO, et al: The pharmacokinetics of acyl, des-acyl, and total ghrelin in healthy human subjects. Eur J Endocrinol 2013;168;821-828.

14 Pacifico L, Poggiogalle E, Costantino F, Anania C, Ferraro F, Chiarelli F, et al: Acylated and nonacylated ghrelin levels and their associations with insulin resistance in obese and normal weight children with metabolic syndrome. Eur J Endocrinol 2009;161:861-870.

15 Koyama KI, Yasuhara D, Nakahara T, Harada T, Uehara M, Ushikai M, et al: Changes in acyl ghrelin, des-acyl ghrelin, and ratio of acyl ghrelin to total ghrelin with short-term refeeding in female inpatients with restrictingtype anorexia nervosa. Horm Metab Res 2010;42:595-598. 
Rodríguez et al.: Novel Molecular Aspects of Ghrelin and Leptin in the Control of Adipobiology and the Cardiovascular System

16 Naufel MF, Bordon M, de Aquino TM, Ribeiro EB, de Abreu Carvalhaes JT: Plasma levels of acylated and total ghrelin in pediatric patients with chronic kidney disease. Pediatr Nephrol 2010;25:2477-2482.

17 Hosoda H, Kojima M, Matsuo H, Kangawa K: Purification and characterization of rat des-Gln14-Ghrelin, a second endogenous ligand for the growth hormone secretagogue receptor. J Biol Chem 2000;275:2199522000.

18 Yang J, Brown MS, Liang G, Grishin NV, Goldstein JL: Identification of the acyltransferase that octanoylates ghrelin, an appetite-stimulating peptide hormone. Cell 2008;132:387-396.

19 Rodríguez A, Gómez-Ambrosi J, Catalán V, Rotellar F, Valenti V, Silva C, et al: The ghrelin O-acyltransferaseghrelin system reduces TNF-alpha-induced apoptosis and autophagy in human visceral adipocytes. Diabetologia 2012;55:3038-3050.

20 Howard AD, Feighner SD, Cully DF, Arena JP, Liberator PA, Rosenblum CI, et al: A receptor in pituitary and hypothalamus that functions in growth hormone release. Science 1996;273:974-977.

-21 Tanaka M, Miyazaki T, Yamamoto I, Nakai N, Ohta Y, Tsushima N, et al: Molecular characterization of chicken growth hormone secretagogue receptor gene. Gen Comp Endocrinol 2003;134:198-202.

22 Leung PK, Chow KB, Lau PN, Chu KM, Chan CB, Cheng CH, et al: The truncated ghrelin receptor polypeptide (GHS-R1b) acts as a dominant-negative mutant of the ghrelin receptor. Cell Signal 2007;19:1011-1022.

23 Müller TD, Müller A, Yi CX, K MH, Meyer CW, Gaylinn BD, et al: The orphan receptor Gpr83 regulates systemic energy metabolism via ghrelin-dependent and ghrelin-independent mechanisms. Nat Commun 2013;4:1968.

24 Zhang Y, Proenca R, Maffei M, Barone M, Leopold L, Friedman JM: Positional cloning of the mouse obese gene and its human homologue. Nature 1994;372:425-432.

25 Gautron L, Elmquist JK: Sixteen years and counting: an update on leptin in energy balance. J Clin Invest 2011; 121:2087-2093.

26 Madej T, Boguski MS, Bryant SH: Threading analysis suggests that the obese gene product may be a helical cytokine. FEBS Lett 1995;373:13-18.

27 Kline AD, Becker GW, Churgay LM, Landen BE, Martin DK, Muth WL, et al: Leptin is a four-helix bundle: secondary structure by NMR. FEBS Lett 1997;407:239-242.

28 Rock FL, Altmann SW, van Heek M, Kastelein RA, Bazan JF: The leptin haemopoietic cytokine fold is stabilized by an intrachain disulfide bond. Horm Metab Res 1996;28:649-652.

-29 Considine RV, Sinha MK, Heiman ML, Kriauciunas A, Stephens TW, Nyce MR, et al: Serum immunoreactiveleptin concentrations in normal-weight and obese humans. N Engl J Med 1996;334:292-295.

30 Caro JF, Kolaczynski JW, Nyce MR, Ohannesian JP, Opentanova I, Goldman WH, et al: Decreased cerebrospinalfluid/serum leptin ratio in obesity: a possible mechanism for leptin resistance. Lancet 1996;348:159-161.

-31 Licinio J, Negrao AB, Mantzoros C, Kaklamani V, Wong ML, Bongiorno PB, et al: Sex differences in circulating human leptin pulse amplitude: clinical implications. J Clin Endocrinol Metab 1998;83:4140-4147.

32 Frühbeck G: Intracellular signalling pathways activated by leptin. Biochem J 2006;393:7-20.

33 Gómez-Ambrosi J, Rodríguez A, Catalán V, Frühbeck G: The bone-adipose axis in obesity and weight loss. Obes Surg 2008;18:1134-1143.

34 Blouet C, Schwartz GJ: Hypothalamic nutrient sensing in the control of energy homeostasis. Behav Brain Res 2010;209:1-12.

35 Harvey J, Ashford ML: Leptin in the CNS: much more than a satiety signal. Neuropharmacology 2003;44:845854.

-36 Scarpace PJ, Matheny M, Pollock BH, Tumer N: Leptin increases uncoupling protein expression and energy expenditure. Am J Physiol 1997;273:E226-230.

-37 Becerril S, Rodríguez A, Catalán V, Sáinz N, Ramírez B, Collantes M, et al: Deletion of inducible nitric-oxide synthase in leptin-deficient mice improves brown adipose tissue function. PLoS One 2010;5:e10962.

-38 Becerril S, Rodríguez A, Catalán V, Sáinz N, Ramírez B, Gómez-Ambrosi J, et al: Transcriptional analysis of brown adipose tissue in leptin-deficient mice lacking inducible nitric oxide synthase: evidence of the role of Med1 in energy balance. Physiol Genomics 2012;44:678-688.

39 Frühbeck G, Gómez-Ambrosi J, Salvador J: Leptin-induced lipolysis opposes the tonic inhibition of endogenous adenosine in white adipocytes. FASEB J 2001;15:333-340.

-40 Rodríguez A, Catalán V, Gómez-Ambrosi J, Frühbeck G: Role of aquaporin-7 in the pathophysiological control of fat accumulation in mice. FEBS Lett 2006;580:4771-4776.

-41 Rodríguez A, Catalán V, Gómez-Ambrosi J, Frühbeck G: Aquaglyceroporins serve as metabolic gateways in adiposity and insulin resistance control. Cell Cycle 2011;10:1548-1556.

-42 Rodríguez A, Catalán V, Gómez-Ambrosi J, García-Navarro S, Rotellar F, Valentí V, et al: Insulin- and leptinmediated control of aquaglyceroporins in human adipocytes and hepatocytes is mediated via the PI3K/Akt/ mTOR signaling cascade. J Clin Endocrinol Metab 2011;96:E586-597.

43 Yasui H, Kubota M, Iguchi K, Usui S, Kiho T, Hirano K: Membrane trafficking of aquaporin 3 induced by epinephrine. Biochem Biophys Res Commun 2008;373:613-617.

-44 Walker CG, Holness MJ, Gibbons GF, Sugden MC: Fasting-induced increases in aquaporin 7 and adipose triglyceride lipase mRNA expression in adipose tissue are attenuated by peroxisome proliferator-activated receptor alpha deficiency. Int J Obes(Lond) 2007;31:1165-1171.

-45 Cummings DE, Purnell JQ, Frayo RS, Schmidova K, Wisse BE, Weigle DS: A preprandial rise in plasma ghrelin levels suggests a role in meal initiation in humans. Diabetes 2001;50:1714-1719. 
Rodríguez et al.: Novel Molecular Aspects of Ghrelin and Leptin in the Control of Adipobiology and the Cardiovascular System

46 Toshinai K, Date Y, Murakami N, Shimada M, Mondal MS, Shimbara T, et al: Ghrelin-induced food intake is mediated via the orexin pathway. Endocrinology 2003;144:1506-1512.

-47 Chen HY, Trumbauer ME, Chen AS, Weingarth DT, Adams JR, Frazier EG, et al: Orexigenic action of peripheral ghrelin is mediated by neuropeptide $Y$ and agouti-related protein. Endocrinology 2004;145:2607-2612.

-48 López M, Lage R, Saha AK, Pérez-Tilve D, Vézquez MJ, Varela L, et al: Hypothalamic fatty acid metabolism mediates the orexigenic action of ghrelin. Cell Metab 2008;7:389-399.

49 Velásquez DA, Martínez G, Romero A, Vázquez MJ, Boit KD, Dopeso-Reyes IG, et al: The central Sirtuin 1/p53 pathway is essential for the orexigenic action of ghrelin. Diabetes 2011;60:1177-1185.

50 Martins L, Fernández-Mallo D, Novelle MG, Vázquez MJ, Tena-Sempere M, Nogueiras R, et al: Hypothalamic mTOR signaling mediates the orexigenic action of ghrelin. PLoS One 2012;7:e46923.

-51 Tschöp M, Weyer C, Tataranni A, Devanarayan V, Ravussin E, Heiman ML: Circulating ghrelin levels are decreased in human obesity. Diabetes 2001;50:707-709.

52 Poykko SM, Ukkola O, Kauma H, Kellokoski E, Horkko S, Kesaniemi YA: The negative association between plasma ghrelin and IGF-I is modified by obesity, insulin resistance and type 2 diabetes. Diabetologia 2005;48: 309-316.

-53 Rodríguez A, Gómez-Ambrosi J, Catalán V, Gil MJ, Becerril S, Sáinz N, et al: Acylated and desacyl ghrelin stimulate lipid accumulation in human visceral adipocytes. Int J Obes (Lond) 2009;33:541-552.

54 Rodríguez A, Gómez-Ambrosi J, Catalán V, Becerril S, Sáinz N, Gil MJ, et al: Association of plasma acylated ghrelin with blood pressure and left ventricular mass in patients with metabolic syndrome. J Hypertens 2010; 28:560-567.

55 Barazzoni R, Zanetti M, Nagliati C, Cattin MR, Ferreira C, Giuricin M, et al: Gastric bypass does not normalize obesity-related changes in ghrelin profile and leads to higher acylated ghrelin fraction. Obesity (Silver Spring) 2013;21:718-722.

56 Catalán V, Gómez-Ambrosi J, Rotellar F, Silva C, Gil MJ, Rodríguez A, et al: The obestatin receptor (GPR39) is expressed in human adipose tissue and is down-regulated in obesity-associated type 2 diabetes mellitus. Clin Endocrinol (Oxf) 2007;66:598-601.

-57 Gurriarán-Rodríguez U, Al-Massadi O, Crujeiras AB, Mosteiro CS, Amil-Diz M, Beiroa D, et al: Preproghrelin expression is a key target for insulin action on adipogenesis. J Endocrinol 2011;210:R1-7.

58 Benso A, St-Pierre DH, Prodam F, Gramaglia E, Granata R, van der Lely AJ, et al: Metabolic effects of overnight continuous infusion of unacylated ghrelin in humans. Eur J Endocrinol 2012;166:911-916.

59 Miegueu P, St Pierre D, Broglio F, Cianflone K: Effect of desacyl ghrelin, obestatin and related peptides on triglyceride storage, metabolism and GHSR signaling in 3T3-L1 adipocytes. J Cell Biochem 2011;112:704-714.

60 Eckel RH, Krauss RM: American Heart Association call to action: obesity as a major risk factor for coronary heart disease. AHA Nutrition Committee. Circulation 1998;97:2099-2100.

61 Kopelman PG: Obesity as a medical problem. Nature 2000;404:635-643.

62 Algahim MF, Sen S, Taegtmeyer H: Bariatric surgery to unload the stressed heart: a metabolic hypothesis. Am J Physiol Heart Circ Physiol 2012;302:H1539-1545.

63 Rahmouni K, Correia ML, Haynes WG, Mark AL: Obesity-associated hypertension: new insights into mechanisms. Hypertension 2005;45:9-14.

64 Frühbeck G: Pivotal role of nitric oxide in the control of blood pressure after leptin administration. Diabetes 1999;48:903-908.

65 Lembo G, Vecchione C, Fratta L, Marino G, Trimarco V, d'Amati G, et al: Leptin induces direct vasodilation through distinct endothelial mechanisms. Diabetes 2000;49:293-297.

-66 Beltowski J, Wojcicka G, Jamroz-Wisniewska A, Marciniak A: Resistance to acute NO-mimetic and EDHFmimetic effects of leptin in the metabolic syndrome. Life Sci 2009;85:557-567.

67 Gálvez B, de Castro J, Herold D, Dubrovska G, Arribas S, González MC, et al: Perivascular adipose tissue and mesenteric vascular function in spontaneously hypertensive rats. Arterioscler Thromb Vasc Biol 2006;26: 1297-1302.

-68 Dunbar JC, Hu Y, Lu H: Intracerebroventricular leptin increases lumbar and renal sympathetic nerve activity and blood pressure in normal rats. Diabetes 1997;46:2040-2043.

69 Vecchione C, Maffei A, Colella S, Aretini A, Poulet R, Frati G, et al: Leptin effect on endothelial nitric oxide is mediated through Akt-endothelial nitric oxide synthase phosphorylation pathway. Diabetes 2002;51:168173.

70 Rodríguez A, Fortuño A, Gómez-Ambrosi J, Zalba G, Díez J, Frühbeck G: The inhibitory effect of leptin on angiotensin II-induced vasoconstriction in vascular smooth muscle cells is mediated via a nitric oxide-dependent mechanism. Endocrinology 2007;148:324-331.

71 Fortuño A, Rodríguez A, Gómez-Ambrosi J, Muñiz P, Salvador J, Díez J, et al: Leptin inhibits angiotensin II-induced intracellular calcium increase and vasoconstriction in the rat aorta. Endocrinology 2002;143: 3555-3560.

72 Villarreal D, Reams G, Samar H, Spear R, Freeman RH: Effects of chronic nitric oxide inhibition on the renal excretory response to leptin. Obes Res 2004;12:1006-1010.

-73 Wold LE, Relling DP, Duan J, Norby FL, Ren J: Abrogated leptin-induced cardiac contractile response in ventricular myocytes under spontaneous hypertension: role of Jak/STAT pathway. Hypertension 2002;39: 69-74. 
Rodríguez et al.: Novel Molecular Aspects of Ghrelin and Leptin in the Control of Adipobiology and the Cardiovascular System

74 Rodríguez A, Frühbeck G, Gómez-Ambrosi J, Catalán V, Sáinz N, Díez J, et al: The inhibitory effect of leptin on angiotensin II-induced vasoconstriction is blunted in spontaneously hypertensive rats. J Hypertens 2006;24: 1589-1597.

75 Henriksen JH, Holst JJ, Moller S, Andersen UB, Bendtsen F, Jensen G: Elevated circulating leptin levels in arterial hypertension: relationship to arteriovenous overflow and extraction of leptin. Clin Sci (Lond) 2000;99:527534.

76 Agata J, Masuda A, Takada M, Higashiura K, Murakami H, Miyazaki Y, et al: High plasma immunoreactive leptin level in essential hypertension. Am J Hypertens 1997;10:1171-1174.

77 Rodríguez A, Gómez-Ambrosi J, Catalán V, Fortuño A, Frühbeck G: Leptin inhibits the proliferation of vascular smooth muscle cells induced by angiotensin II through nitric oxide-dependent mechanisms. Mediators Inflamm 2010;2010:105489.

78 Schroeter MR, Stein S, Heida NM, Leifheit-Nestler M, Cheng IF, Gogiraju R, et al: Leptin promotes the mobilization of vascular progenitor cells and neovascularization by NOX2-mediated activation of MMP9. Cardiovasc Res 2012;93:170-180.

79 Rodríguez A, Catalán V, Becerril S, Gil MJ, Mugueta C, Gómez-Ambrosi J, et al: Impaired adiponectin-AMPK signalling in insulin-sensitive tissues of hypertensive rats. Life Sci 2008;83:540-549.

80 Oda A, Taniguchi T, Yokoyama M: Leptin stimulates rat aortic smooth muscle cell proliferation and migration. Kobe J Med Sci 2001;47:141-150.

81 Schroeter MR, Leifheit-Nestler M, Hubert A, Schumann B, Gluckermann R, Eschholz N, et al: Leptin promotes neointima formation and smooth muscle cell proliferation via NADPH oxidase activation and signalling in caveolin-rich microdomains. Cardiovasc Res 2013;99:555-565.

82 Bohlen F, Kratzsch J, Mueller M, Seidel B, Friedman-Einat M, Witzigmann H, et al: Leptin inhibits cell growth of human vascular smooth muscle cells. Vascul Pharmacol 2007;46:67-71.

-83 Trovati M, Doronzo G, Barale C, Vaccheris C, Russo I, Cavalot F: Leptin and Vascular Smooth Muscle Cells. Curr Pharm Des 2014;20:625-634.

84 Lin Y, Matsumura K, Fukuhara M, Kagiyama S, Fujii K, Iida M: Ghrelin acts at the nucleus of the solitary tract to decrease arterial pressure in rats. Hypertension 2004;43:977-982.

85 Matsumura K, Tsuchihashi T, Fujii K, Abe I, Iida M: Central ghrelin modulates sympathetic activity in conscious rabbits. Hypertension 2002;40:694-699.

-86 Iglesias MJ, Pineiro R, Blanco M, Gallego R, Diéguez C, Gualillo 0, et al: Growth hormone releasing peptide (ghrelin) is synthesized and secreted by cardiomyocytes. Cardiovasc Res 2004;62:481-488.

87 Beiras-Fernández A, Kreth S, Weis F, Ledderose C, Pottinger T, Diéguez C, et al: Altered myocardial expression of ghrelin and its receptor (GHSR-1a) in patients with severe heart failure. Peptides 2010;31:2222-2228.

-88 Mao Y, Tokudome T, Otani K, Kishimoto I, Miyazato M, Kangawa K: Excessive sympathoactivation and deteriorated heart function after myocardial infarction in male ghrelin knockout mice. Endocrinology 2013;154: 1854-1863.

89 Nagaya N, Uematsu M, Kojima M, Ikeda Y, Yoshihara F, Shimizu W, et al: Chronic administration of ghrelin improves left ventricular dysfunction and attenuates development of cardiac cachexia in rats with heart failure. Circulation 2001;104:1430-1435.

90 Nagaya N, Moriya J, Yasumura Y, Uematsu M, Ono F, Shimizu W, et al: Effects of ghrelin administration on left ventricular function, exercise capacity, and muscle wasting in patients with chronic heart failure. Circulation 2004;110:3674-3679.

91 Schwenke DO, Tokudome T, Kishimoto I, Horio T, Cragg PA, Shirai M, et al: One dose of ghrelin prevents the acute and sustained increase in cardiac sympathetic tone after myocardial infarction. Endocrinology 2012; 153:2436-2443.

92 Bedendi I, Alloatti G, Marcantoni A, Malan D, Catapano F, Ghe C, et al: Cardiac effects of ghrelin and its endogenous derivatives des-octanoyl ghrelin an des-Gln14-ghrelin. Eur J Pharmacol 2003;476:87-95.

93 Ma Y, Zhang L, Edwards JN, Launikonis BS, Chen C: Growth hormone secretagogues protect mouse cardiomyocytes from in vitro ischemia/reperfusion injury through regulation of intracellular calcium. PLoS One 2012;7:e35265.

94 Rodríguez A, Gómez-Ambrosi J, Catalán V, Becerril S, Sáinz N, Ramírez B, et al: Vasodilator effect of ghrelin in the rat aorta. Endocrinol Nutr 2008;55:448-453.

95 Kawczynska-Drozdz A, Olszanecki R, Jawien J, Brzozowski T, Pawlik WW, Korbut R, et al: Ghrelin inhibits vascular superoxide production in spontaneously hypertensive rats. Am J Hypertens 2006;19:764-767.

-96 Tesauro M, Schinzari F, Rovella V, Di Daniele N, Lauro D, Mores N, et al: Ghrelin restores the endothelin 1/ nitric oxide balance in patients with obesity-related metabolic syndrome. Hypertension 2009;54:995-1000.

-97 Baldanzi G, Filigheddu N, Cutrupi S, Catapano F, Bonissoni S, Fubini A, et al: Ghrelin and des-acyl ghrelin inhibit cell death in cardiomyocytes and endothelial cells through ERK1/2 and PI 3-kinase/AKT. J Cell Biol 2002;159: 1029-1037.

98 Yang C, Wang Y, Liu H, Li N, Sun Y, Liu Z, et al: Ghrelin protects H9c2 cardiomyocytes from angiotensin II-induced apoptosis through the endoplasmic reticulum stress pathway. J Cardiovasc Pharmacol 2012;59: 465-471.

99 Li WG, Gavrila D, Liu X, Wang L, Gunnlaugsson S, Stoll LL, et al: Ghrelin inhibits proinflammatory responses and nuclear factor- $\kappa B$ activation in human endothelial cells. Circulation 2004;109:2221-2226. 
Rodríguez et al.: Novel Molecular Aspects of Ghrelin and Leptin in the Control of Adipobiology and the Cardiovascular System

100 Cao Y, Tang J, Yang T, Ma H, Yi D, Gu C, et al: Cardioprotective effect of ghrelin in cardiopulmonary bypass involves a reduction in inflammatory response. PLoS One 2013;8:e55021.

101 Aydin S, Guzel SP, Kumru S, Akin O, Kavak E, Sahin I, et al: Serum leptin and ghrelin concentrations of maternal serum, arterial and venous cord blood in healthy and preeclamptic pregnant women. J Physiol Biochem 2008; 64:51-59.

102 Oner-Iyidogan Y, Kocak H, Gurdol F, Oner P, Issever H, Esin D: Circulating ghrelin levels in obese women: a possible association with hypertension. Scand J Clin Lab Invest 2007;67:568-576.

103 Yang D, Liu Z, Luo Q: Plasma ghrelin and pro-inflammatory markers in patients with obstructive sleep apnea and stable coronary heart disease. Med Sci Monit 2013;19:251-256.

104 Vörös K, Prohászka Z, Kaszás E, Alliquander A, Terebesy A, Horváth F, et al: Serum ghrelin level and TNFalpha/ghrelin ratio in patients with previous myocardial infarction. Arch Med Res 2012;43:548-554.

105 Uchegbu EC, Kopelman PG: Cardiovascular risks in obesity. J Endocrinol Invest 2002;25:915-918.

106 Rodríguez A, Becerril S, Valentí V, Ramírez B, Martín M, Méndez-Giménez L, et al: Sleeve gastrectomy reduces blood pressure in obese (fa/fa) Zucker rats. Obes Surg 2012;22:309-315.

107 Rodríguez A, Becerril S, Valentí V, Moncada R, Méndez-Giménez L, Ramírez B, et al: Short-term effects of sleeve gastrectomy and caloric restriction on blood pressure in diet-induced obese rats. Obes Surg 2012;22:14811490.

108 Prior LJ, Davern PJ, Burke SL, Lim K, Armitage JA, Head GA: Exposure to a high-fat diet during development alters leptin and ghrelin sensitivity and elevates renal sympathetic nerve activity and arterial pressure in rabbits. Hypertension 2014;63:338-345. 